\title{
Oral Hygiene Status and Gingival Status of the 12- to 15-year- old Orphanage Children Residing in Delhi State: A Cross-sectional Study
}

\author{
Aarti Kumari ${ }^{1}$, Charumohan Marya ${ }^{2}$, Sukhvinder Singh Oberoi ${ }^{3}$, Ruchi Nagpal ${ }^{4}$, Sourav Chandra Bidyasagar ${ }^{5}$, \\ Pratibha Taneja ${ }^{6}$
}

\begin{abstract}
Aim and objective: To assess oral hygiene status and practices among 12- to 15-year-old orphanage children in Delhi State, India. Study design: In this cross-sectional study, a one-stage cluster sampling design was carried out with orphanages as a cluster unit to assess oral hygiene status and practices among orphanage children in Delhi state, India.

Results: The majority of the orphanage children had good oral hygiene status (53.8\%) followed by fair (32.3\%) and poor (13.9\%) oral hygiene status. A large proportion (48.3\%) of the orphanage children had mild gingival status followed by moderate (34.9\%) and severe (16.8\%) gingival status. No statistical difference was reported for the distribution of oral hygiene status and gingival score across all the age-groups. Most (53\%) of the orphanage children among all age-groups had good plaque status. The correlation of gingival index (GI) scores with plaque index (PI) score and oral hygiene index-simplified (OHI-S) scores showed a significant correlation of Gl scores with PI scores $(r=0.815)$ and OHI-S scores $(r=0.799)$. Conclusion: The oral hygiene practices and oral hygiene status along with gingival status were found to be satisfactory among orphanage children in the present study.

Clinical significance: Gingival and periodontal diseases have a high prevalence among orphanages because of poor hygiene practices. Untreated oral diseases could lead to general health problems. Thus, the preventive strategies can be planned with the exact knowledge of the oral hygiene status of these special needs children in Delhi state.
\end{abstract}

Keywords: Brushing frequency, Gingival status, Oral hygiene status, Orphanage children, Plaque status. International Journal of Clinical Pediatric Dentistry (2021): 10.5005/jp-journals-10005-1989

\section{INTRODUCTION}

The future of any nation are children and to strengthen a nation, a healthy, protected, educated, and well-developed child population that will grow up to be productive citizens of the country is a must. ${ }^{1}$ The primary caretakers and saviors of a child are parents but woefully there are thousands of children who lead their lives without one. The parents of such children are either being dead or incapable of their upbringing and such section of children in society are termed as "orphans". 1,2 An orphan is a child who has either lost one or both parents. In the Islam religion, children of unknown parentage are also included in this definition. ${ }^{3}$

Due to unemployment, increased migration of families, broken families, increasing poverty, neglect, abuse and violence, armed conflicts, natural and man-made disasters, decreasing resources in rural areas, and the attraction of cities, a majority of these children are placed in orphanages. ${ }^{4,5}$ They are the vulnerable group of children facing numerous challenges such as a high risk of poor health. ${ }^{6}$

According to a recent United Nations International Children Emergency Fund (UNICEF) report, there are between 143 million to 210 million orphans in the world and nearly 87.6 million are in Asia alone. ${ }^{7}$ India constitutes a major part of the under 18-year population (UNICEF 2005) been the second most populated country in the world. ${ }^{8,9}$ Of the total child population in the year $2010,6.8 \%$, i.e., $25,000,000$ were estimated to be orphans. ${ }^{1,2,8,9}$

Orphans being a deprived community have little control over their own lives. Non-governmental organizations (NGOs) or social workers take care of these orphans with limited funds and support
${ }^{1}$ Department of Public Health Dentistry, Hazaribag College of Dental Sciences and Hospital, Hazaribag, Jharkhand, India

2,4,6 Department of Public Health Dentistry, Sudha Rustagi College of Dental Sciences and Research, Faridabad, Haryana, India

${ }^{3}$ Department of Public Health Dentistry, Genesis Institute of Dental Sciences and Research, Ferozpur, Punjab, India

${ }^{5}$ Department of Public Health Dentistry, Institute of Dental Sciences, SOA University, Bhubaneswar, Odisha, India

Corresponding Author: Aarti Kumari, Department of Public Health Dentistry, Hazaribag College of Dental Sciences and Hospital, Hazaribag, Jharkhand, India, Phone: +91 9717635809, e-mail: kumariaarti2013@gmail.com

How to cite this article: Kumari A, Marya C, Oberoi SS, et al. Oral Hygiene Status and Gingival Status of the 12- to 15-year-old Orphanage Children Residing in Delhi State: A Cross-sectional Study. Int J Clin Pediatr Dent 2021;14(4):482-487.

Source of support: Nil

Conflict of interest: None

to provide them with the basic amenities of life like food, shelter, clothing as well as education and health. ${ }^{6,7}$ The pattern of living in an orphanage is entirely different from living with family. Therefore, it has been hypothesized that children residing in orphanages since being underprivileged have a different pattern of oral diseases and quality of life and receives no similar care as other children do from their parents. ${ }^{10,11}$ 
The orphanage children are at an increased risk of developing oral diseases and disorders as it is one of the unmet healthcare which give rise not only to physical but also to economic, social, and psychological problems that impair the quality of life. ${ }^{6}$ Several factors contributing to these unmet healthcare needs among orphans are, lack of availability of dental healthcare services, financial resources, lack of perceived needs for dental care, less motivation by caretakers, low priority given to dental care when compared with general health and finally the cost of treatment puts them on the potential risk of poor general as well as oral health. 711,12

A high prevalence of gingival and periodontal diseases has been observed in children of orphanages. Oral hygiene practices are very poor among this group. Untreated oral diseases could lead to general health problems. Recognition of these problems is essential to provide optimum oral health for these deprived children. ${ }^{10}$

Many studies have evaluated the oral health status and treatment needs of different high-risk groups like the mentally challenged, physically handicapped, geriatric population but there is a paucity of studies describing the oral health status and oral hygiene practices of orphanage children in India. So, the current study was aimed at assessing the oral hygiene status and practices among orphanage children in Delhi State, India.

\section{Materials and Methods}

The current study was carried out to assess the oral hygiene status and practices of 12- to 15-year-old children residing in orphanages in Delhi state. Sample size estimation was derived from the pilot study which was done in one of the orphanages in Delhi and was calculated to be 900 and to avoid bias, the participants of the pilot study were not included again in the main study.

\section{Study Design}

At the beginning of the study, the list of all the orphanages in Delhi state was obtained from the Department of Social Justice and Empowerment, and the Indian Orphanage Network Children's helpline which comprised 63 orphanages. After obtaining the complete addresses and telephone numbers of the orphanages, the number of working orphanages was determined to be 54 . The study sample was collected using a cluster sampling design with orphanages as a cluster unit.

\section{Inclusion and Exclusion Criteria}

The systemically healthy orphanage children in the age-group of 12 to 15 years who were willing for examination and also gave verbal consent were included. Inmates who were undergoing orthodontic treatment and other conditions that interfere with the clinical oral examination were excluded. Also, inmates, who had un-erupted index teeth for oral hygiene index-simplified (OHI-S), gingival index $(\mathrm{Gl})$, and plaque index $(\mathrm{Pl})$ were excluded along with differently-abled inmates.

\section{Ethical Considerations}

The study protocol was reviewed and ethical clearance was sought from the Ethical Committee. The written permission to examine the oral cavity of these children was obtained from the concerned authorities of the orphanages. Before the examination, verbal consent was taken from every subject.

\section{Training and Calibration of the Examiner}

The clinical examination of all the study subjects was done by a single examiner who was trained and calibrated in the Department of Public Health Dentistry. The intra-examiner variability was checked by performing the repeat examination of $10 \%$ randomly selected subjects and intra-examiner reliability was assessed using kappa statistics. The kappa values ranged from 0.78 to 0.83 for oral hygiene status, plaque scores, and gingival scores.

\section{Data Collection}

Data were collected by a combination of a structured interview and clinical examination. The data were recorded on a pretested, validated, structured pro forma with open- and close-ended questions. A structured interview was conducted to collect information on demographic characteristics (name, age, and gender), and oral hygiene practices (frequency, method of cleaning teeth, type of material used) of the study population.

On completion of the interview, the clinical oral examination for the oral hygiene status of orphans was assessed using $\mathrm{OHI}-\mathrm{S}$ given by Greene and Vermillion, ${ }^{13}$ and PI given by Silness and Loe. ${ }^{14}$ The gingival status was assessed using the GI given by Loe and Silness. ${ }^{15}$

\section{Statistical Analysis}

The data were recorded and transferred from the assessment form to the computer and the master chart was created in the excel sheet using Microsoft Excel Software. The SPSS version 16 software was used for the statistical analysis. The data were summarized in the form of mean and standard deviation for numerical data, and frequencies and percentages for categorical data.

The normality of the data was checked using Shapiro-Wilk's test. For those variables which failed to achieve normal distribution for the inferential statistics, the non-parametric tests were used. Mann-Whitney $U$ test was used for comparison of the mean values between two groups and for comparison of the mean values between three or more groups the Kruskal-Wallis test was used. The distribution of the categorical variables was compared using the Chi-square test. The $p$ value of $<0.05$ was considered to be statistically significant.

\section{Results}

The study population consisted of 626 (69.6\%) males and 274 (30.4\%) females. There were 304 (33.78\%) subjects from 12 years of agegroup, 279 (31\%) subjects from 13 years of age-group, 159 (17.67\%) subjects from 14 years of age-group, and 158 (17.55\%) subjects from 15 years of age-group.

The majority of the orphanage children $(720,80.0 \%)$ cleaned their teeth once a day, followed by twice a day (168, 18.7\%), irregularly $(11,1.2 \%)$, and only $1(0.1 \%)$ subject cleaned teeth more than two times a day. Cleaning of teeth once daily was significantly more among 12-year $(250,82.2 \%)$ and 15 -year $(133,84.2 \%)$ agegroups in comparison to 13-year $(209,74.9 \%)$ and 14-year (128, $80.5 \%)$ age-groups whereas the irregular frequency of cleaning teeth was reported to be significantly more among 12-year-old orphanage children $(10,3.3 \%)$ in comparison to 13 -year $(1,0.3 \%)$, 14 -year $(0.0 \%)$, and 15 -year $(0.0 \%)$ age-groups. Twice daily was significantly more among 13 -year $(68,24.4 \%)$ age-groups. Cleaning of teeth once daily and irregularly was reported to be significantly more among males $(517,82.6 \%$ and $10,1.6 \%$, respectively), whereas twice daily was significantly more among females (70, 25.5\%).

A toothbrush was used by the majority $(899,99.89 \%)$ of orphanage children for cleaning their teeth including male $(625$, $99.8 \%)$ and female $(274,100.0 \%)$ orphanage children. The majority $(897,99.7 \%)$ of the subjects were using toothpaste for cleaning their teeth followed by toothpowder $(3,0.3 \%)$. 


\section{Oral Hygiene Status}

Most of the orphanage children had good oral hygiene status (53.8\%) followed by fair (32.3\%) and poor (13.9\%) oral hygiene status. Good oral hygiene status score was found to be more among 13-year-old orphanage children (60.2\%), the fair was more among 15 -year-old children (41.1\%), and poor oral hygiene status was reported to be more among 12 -and 15 -year-old orphanage children ( $15.5 \%$ and $14.6 \%$, respectively) with no statistically significant difference across the age-groups (Table 1).

The genderwise comparison of oral hygiene status showed that fair (34.2\%) and poor (15.7\%) oral hygiene status was significantly more among males and good (62.0\%) oral hygiene status was significantly more among females (Table 1).

The mean OHI-S score was $1.51 \pm 1.30$ among orphanage children. The mean oral hygiene was found to be maximum among 15 years old $(1.68 \pm 1.16)$ followed by 12 years old $(1.56 \pm 1.42), 14$ years old $(1.51 \pm 1.21)$, and least among 13-year-old orphanage children $(1.36 \pm 1.26)$ with no statistically significant difference across the age-groups. The mean OHI-S score was poor among males $(1.64 \pm 1.33)$ when compared with females $(1.23 \pm 1.16)$ with no statistically significant difference between them (Table 1).

\section{Plaque Status}

Most (53\%) of the orphanage children had good plaque status. Excellent plaque status was found to be more among 13 years of age-group orphanage children (29.4\%), good (58.2\%), and fair (24.7\%) were more among the 15-year-old age-group and poor plaque status was found more among 14 years of age-group orphanage children (3.8\%). The excellent score was significantly more among females (31.8\%) whereas good (55\%), fair (24\%), and poor (2.4\%) plaque status scores were significantly more among males (Table 2 ).

Mean PI scores were maximum among 15 years $(0.75 \pm 0.51)$ of age-group followed by 12 years $(0.70 \pm 0.54), 14$ years $(0.70 \pm 0.57)$, and with least among the 13 -year age-group $(0.63 \pm 0.58)$ with no statistically significant difference across the age-groups. The mean plaque score among males $(0.73 \pm 0.55)$ was significantly more as compared to female orphanage children $(0.58 \pm 0.54)$ (Table 2$)$.

\section{Gingival Status}

Most (48.3\%) of the orphanage children had mild gingival status. The prevalence of gingival status score across the age-groups has statistically no significant difference ( $p$ value $>0.05$ ). Mild gingival status was found to be more among 13 years old orphanage children (53.8\%), moderate was more among 15 years old (41.8\%), and severe was more among 12 years old (18.5\%). Mild gingival status was found to be significantly more among female orphanage children (57.3\%) whereas moderate (37.4\%) and severe (18.2\%) gingival status score was found to be significantly more among male orphanage children (Table 3).

Mean $\mathrm{Gl}$ score was found to be maximum among 15 -year $(0.48$ \pm 0.54 ) age-group and least among 13-year-old orphanage children $(0.38 \pm 0.55)$ with no statistically significant difference across the age-groups. Among males $(0.49 \pm 0.60)$ in comparison to females $(0.32 \pm 0.49)$, the mean Gl score was significantly more (Table 3$)$.

\section{Correlation between GI Scores with PI Score and OHI-S Scores}

The correlation of $\mathrm{Gl}$ scores with PI score and OHI-S scores showed that a significant correlation of Gl scores with PI scores $(r=0.815)$ and OHI-S scores $(r=0.799)$.

A statistical difference was seen for the mean OHI-S score, $\mathrm{PI}$ score, and Gl scores according to the frequency of cleaning teeth. The mean OHI-S score, PI score, and GI score were significantly better among subjects who were cleaning their teeth two or more times a day as compared to once daily and irregular frequency of cleaning their teeth (Table 4).

\section{Discussion}

Orphans are those children who have lost either one or both parents. ${ }^{16}$ In India, NGOs or social workers take care of orphanage children without realizing that oral health is an integral part of children's overall well-being. ${ }^{7}$ However, to date, relatively few studies have been conducted on orphanage children.

In the present study, most (80\%) of the children cleaned their teeth once daily, followed by twice daily (18.7\%), irregularly (1.2\%),

Table 1: Distribution of oral hygiene index-simplified (OHI-S) scores among different age-groups and gender

\begin{tabular}{|c|c|c|c|c|c|}
\hline \multirow[b]{3}{*}{ Age category } & \multicolumn{5}{|c|}{ OHI-S status } \\
\hline & Good & Fair & Poor & Total & OHI-S \\
\hline & $n(\%)$ & $n(\%)$ & $n(\%)$ & $N(\%)$ & Mean \pm S.D. \\
\hline 12 years & $162(53.3)$ & $95(31.2)$ & $47(15.5)$ & $304(100.0)$ & $1.56 \pm 1.42$ \\
\hline 13 years & $168(60.2)$ & $76(27.2)$ & $35(12.5)$ & $279(100.0)$ & $1.36 \pm 1.26$ \\
\hline 14 years & $84(52.8)$ & $56(34.6)$ & $20(12.6)$ & $159(100.0)$ & $1.51 \pm 1.21$ \\
\hline 15 years & $70(44.3)$ & $65(41.1)$ & $23(14.6)$ & $158(100.0)$ & $1.68 \pm 1.16$ \\
\hline \multirow[t]{2}{*}{ Total } & $484(53.8)$ & $291(32.3)$ & 125 (13.9) & $900(100.0)$ & $1.51 \pm 1.30$ \\
\hline & \multicolumn{3}{|c|}{$p$ value $^{\mathrm{a}}=0.054^{\#}$} & & $p$ value $^{\mathrm{b}}=0.535^{\#}$ \\
\hline Male & $314(50.2)$ & $214(34.2)$ & $98(15.7)$ & $626(100.0)$ & $1.64 \pm 1.33$ \\
\hline Female & $170(62.0)$ & $77(28.1)$ & $27(9.9)$ & $274(100.0)$ & $1.23 \pm 1.16$ \\
\hline \multirow[t]{2}{*}{ Total } & $484(53.8)$ & $291(32.3)$ & 125 (13.9) & $900(100.0)$ & \\
\hline & \multicolumn{3}{|c|}{$p$ value $^{\mathrm{a}}=0.003^{*}$} & & $p$ value $^{c}<0.001^{*}$ \\
\hline
\end{tabular}

\footnotetext{
\#Not-significant

*Statistically significant

${ }^{\text {a } C h i-s q u a r e ~ t e s t ~}$

${ }^{\mathrm{b}}$ Kruskal-Wallis test

'Mann-Whitney $U$ test
} 
Oral Hygiene Status and Gingival Status of the 12- to 15-year-old Orphanage Children

Table 2: Distribution of study population according to plaque status among different age-groups and gender

\begin{tabular}{|c|c|c|c|c|c|c|}
\hline \multirow[b]{3}{*}{ Age category } & \multicolumn{6}{|c|}{ Plaque status } \\
\hline & Excellent & Good & Fair & Poor & Total & \\
\hline & $n(\%)$ & $n(\%)$ & $n(\%)$ & $n(\%)$ & $N(\%)$ & Mean $\pm S D$ \\
\hline 12 years & $62(20.4)$ & $168(55.3)$ & $72(23.7)$ & $2(0.7)$ & $304(100.0)$ & $0.7 \pm 0.54$ \\
\hline 13 years & $82(29.4)$ & $137(49.1)$ & $53(19.0)$ & $7(2.5)$ & $279(100.0)$ & $0.63 \pm 0.58$ \\
\hline 14 years & $36(22.6)$ & $80(50.3)$ & $37(23.3)$ & $6(3.8)$ & $159(100.0)$ & $0.7 \pm 0.57$ \\
\hline 15 years & $24(15.2)$ & $92(58.2)$ & $39(24.7)$ & $3(1.9)$ & $158(100.0)$ & $0.75 \pm 0.51$ \\
\hline \multirow[t]{2}{*}{ Total } & $204(22.7)$ & $477(53.0)$ & $201(22.3)$ & $18(2.0)$ & $900(100.0)$ & $0.68 \pm 0.2$ \\
\hline & \multicolumn{4}{|c|}{$p$ value $^{\mathrm{a}}=0.018^{*}$} & & $0.146^{\#}$ \\
\hline Male & $117(18.7)$ & $344(55.0)$ & $150(24)$ & $15(2.4)$ & $626(100.0)$ & $0.73 \pm 0.55$ \\
\hline Female & $87(31.8)$ & $133(48.5)$ & $51(18.6)$ & $3(1.1)$ & $274(100.0)$ & $0.58 \pm 0.54$ \\
\hline \multirow[t]{2}{*}{ Total } & $204(22.7)$ & $477(53.0)$ & $201(22.3)$ & $18(2.0)$ & $900(100.0)$ & \\
\hline & \multicolumn{5}{|c|}{$p$ value $^{\mathrm{a}}<0.001^{*}$} & $<0.001 *$ \\
\hline
\end{tabular}

*Statistically significant

\#Non-significant

${ }^{\mathrm{a} C h i-s q u a r e ~ t e s t ~}$

Table 3: Distribution of study population according to gingival status among different age-groups and gender

\begin{tabular}{|c|c|c|c|c|c|}
\hline \multirow[b]{3}{*}{ Age category } & \multicolumn{5}{|c|}{ Gingival status } \\
\hline & Mild gingivitis & Moderate gingivitis & Severe gingivitis & Total & \\
\hline & $n(\%)$ & $n(\%)$ & $n(\%)$ & $N(\%)$ & Mean $\pm S D$ \\
\hline 12 years & $145(47.7)$ & $103(33.9)$ & $56(18.5)$ & $304(100.0)$ & $0.47 \pm 0.6$ \\
\hline 13 years & $150(53.8)$ & $88(31.5)$ & $41(14.7)$ & $279(100.0)$ & $0.38 \pm 0.55$ \\
\hline 14 years & $74(46.5)$ & $57(35.8)$ & $28(17.6)$ & $159(100.0)$ & $0.46 \pm 0.6$ \\
\hline 15 years & $66(41.8)$ & $66(41.8)$ & $26(16.5)$ & $158(100.0)$ & $0.48 \pm 0.54$ \\
\hline \multirow[t]{2}{*}{ Total } & $435(48.3)$ & $314(34.9)$ & $151(16.8)$ & $900(100.0)$ & $0.44 \pm 0.57$ \\
\hline & \multicolumn{3}{|c|}{$p$ value $^{\mathrm{a}}=0.450^{\#}$} & & $0.202^{\#}$ \\
\hline Male & $278(44.4)$ & $234(37.4)$ & $114(18.2)$ & $626(100.0)$ & $0.49 \pm 0.6$ \\
\hline Female & $157(57.3)$ & $80(29.2)$ & $37(13.5)$ & $274(100.0)$ & $0.32 \pm 0.49$ \\
\hline \multirow[t]{2}{*}{ Total } & $435(48.3)$ & $314(34.9)$ & $151(16.8)$ & $900(100.0)$ & \\
\hline & \multicolumn{3}{|c|}{$p$ value $^{a}=0.003^{*}$} & & $<0.001 *$ \\
\hline
\end{tabular}

*Statistically significant

\#Non-significant

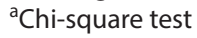

Table 4: Comparison of OHI-S score, PI score, and GI score with a frequency of cleaning teeth among the study population

\begin{tabular}{|c|c|c|c|c|}
\hline \multicolumn{2}{|c|}{ Frequency of cleaning } & \multirow{2}{*}{$\begin{array}{l}\text { Oral hygiene } \\
\text { index-simplified }\end{array}$} & \multirow{2}{*}{$\begin{array}{l}\begin{array}{l}\text { Plaque } \\
\text { index }\end{array} \\
0.70\end{array}$} & \multirow{2}{*}{$\begin{array}{l}\text { Gingival } \\
\text { index }\end{array}$} \\
\hline Once (1) & Mean & & & \\
\hline & SD & 1.28 & 0.54 & 0.57 \\
\hline \multirow{2}{*}{$\begin{array}{l}\text { Two or more } \\
\text { times a day ( } 2 \text { ) }\end{array}$} & Mean & 1.26 & 0.57 & 0.32 \\
\hline & SD & 1.30 & 0.56 & 0.54 \\
\hline \multirow[t]{2}{*}{ Irregular (3) } & Mean & 2.69 & 1.18 & 0.95 \\
\hline & SD & 1.32 & 0.61 & 0.74 \\
\hline \multirow[t]{2}{*}{ Total } & Mean & 1.51 & 0.68 & 0.44 \\
\hline & SD & 1.29 & 0.55 & 0.57 \\
\hline \multicolumn{2}{|c|}{$p$ value $^{\mathrm{a}}$} & $0.001^{*}$ & $0.001^{*}$ & $<0.001^{*}$ \\
\hline \multicolumn{2}{|c|}{ Post hoc comparison ${ }^{\mathrm{b}}$} & $3>1>2$ & $3>1>2$ & $3>1>2$ \\
\hline
\end{tabular}

and more than two times a day (0.1\%). In the study by Shanbhog et al., ${ }^{4}$ among 12- to 14-year-old orphanage children in Mysore district, Karnataka, $95.1 \%$ of orphans cleaned their teeth once daily, and Gaur et al., ${ }^{17}$ most (99.4\%) of the juvenile group children brushed their teeth once. However, all (100\%) orphanage children cleaned their teeth once daily in the study by Ojahanon et al. ${ }^{6}$ and Sushanth et al. ${ }^{18}$

Cleaning of teeth twice daily was $18.70 \%$ among orphanage children in the present study. The current study was not in accordance with the studies done by Camacho et al., ${ }^{19}$ in which $37.2 \%$ of the girls brushed their teeth two or more times a day and $62.8 \%$ brushed their teeth once daily, Singh et al., ${ }^{12}$ among 12 -yearold Ashrama children in Udupi district, Karnataka, in which $66.6 \%$ of orphanage children brushed two or more times a day and Shanbhog et al. ${ }^{4}$ reported that $100.0 \%$ of orphanage children were cleaning their teeth twice daily. A better frequency of cleaning teeth was reported in these studies when compared with the present study.

In the present study, toothbrush (99.90\%) and toothpaste $(99.70 \%)$ were used by most of the orphanage children for cleaning 
their teeth. The findings of the present study were in accordance with the studies were done by Singh et al. ${ }^{12}(100.0 \%)$, Kumar et al. ${ }^{2}$ (90.8\%), Shanbhog et al..$^{4}(100.0 \%)$, and Hans et al. ${ }^{10}(82 \%)$ of the orphanage children used toothbrush and toothpaste for cleaning their teeth.

Whereas this was in contrast with the studies reported by Srinivas et al., ${ }^{5}$ Khare et al., ${ }^{1}$ Gupta et al., ${ }^{7}$ and Al-Maweri et al., ${ }^{20}$ in which the use of toothbrush and toothpaste was much lower when compared with the present study. The non-availability of brushing aids (toothbrush and toothpaste), lack of financial resources, and lack of guidance, and assistance for brushing in these institutions could be the reason for this. ${ }^{17}$

The majority (53.3\%) of the orphanage children in the present study had good oral hygiene status, followed by fair (41.1\%) and poor (14.6\%). However, in the study by Al-Jobair et al., ${ }^{3}$ in which the $\mathrm{OHI}$ index by James et al. was used, the majority (75.6\%) of the subjects had fair oral hygiene status, followed by poor (17.8\%) and good (6.7\%). The present study was in contrast with the studies by Shanbhog et al., ${ }^{4}$ Gaur et al., ${ }^{17}$ and Ojahanon et al., ${ }^{6} 32.8 \%, 61.36 \%$, and $21 \%$ of children, respectively, had poor oral hygiene index scores which were higher than the present study.

The oral hygiene status of the females (higher prevalence of good score) was found to be significantly better than male orphanage children (higher prevalence of fair and poor oral hygiene scores). Similar findings have been reported by Gaur et al., ${ }^{17}$ the boys of the juvenile group had a poor $\mathrm{OHI}(61.36 \%)$ with comparatively better (58.97\%) oral hygiene status among females, and Ojahanon et al., ${ }^{6}$ poor oral hygiene status was more among males $(29.4 \%)$ in comparison to female orphanage children (14.3\%).

The poor oral hygiene was more in the males which may be related to the cumulative accumulation of deposits over the years and lack of guidance for the maintenance of proper oral hygiene. The number among females with poor oral hygiene status was less due to possible growing awareness about esthetics at puberty. ${ }^{6}$

The overall mean plaque score among orphans in the current study was $0.68 \pm 0.20$. However, in the study carried out by Al-Jobair et al., ${ }^{3}$ the mean plaque score among orphanage children was 1.35 \pm 0.55 which was higher than that in the present study.

Several studies have shown that teaching in schools and institutions like orphanages can be effective in terms of improving both knowledge and health outcome measures. ${ }^{21-23}$ It can be suggested that an oral health promotion program can be useful in improving the oral hygiene status of orphanage children.

The mean gingival score among orphanage children was 0.44 \pm 0.57 in the present study which was not in agreement with the study carried out by Al-Jobair et al., ${ }^{3}(1.0 \pm 0.28)$ which was found to be a higher mean $\mathrm{Gl}$ score compared to the present study.

The majority (48.3\%) of the orphanage children in the present study had mild gingival status, followed by moderate $(34.9 \%)$ and severe (16.8\%). The findings of the current study were not in agreement with the study done by Mazhari et al., ${ }^{24}$ using the modified gingival index (MGI) criteria found that $67 \%$ of orphans had poor gingival scores.

A highly significant positive correlation between $\mathrm{OHI}-\mathrm{S}$ and GI was reported by Shanbhog et al., ${ }^{4}$ suggesting children with good oral hygiene have better gingival health status which was corresponding to the present study. Similarly, Al-Jobair et al. ${ }^{3}$ reported that the $\mathrm{Gl}$ scores were found to be correlated with $\mathrm{PI}$ scores, as children with high mean Gl scores had the highest mean
PI scores and those with lowest mean GI scores had the lowest mean PI scores. The better plaque and gingival scores in the present study might be attributed to the fact that nowadays oral hygiene aids are being funded by NGOs and a focus is there on the maintenance of oral health at these institutions.

The mean OHI-S score, PI score, and GI scores were found better among participants who were cleaning teeth two or more times a day comparative to once or irregular frequency of cleaning teeth. These results were in agreement with studies carried out by Khursheed et al. ${ }^{25}$ among (20-40 years) young adult patients in Iraq, the highest mean plaque and gingival score were found in subjects with no brushing frequency and tends to decrease with increasing frequency of toothbrushing and Kuppuswamy et al. ${ }^{26}$ among (10-16 years) school children, a much higher OHI-S score was found among never brushing teeth when compared more than two times a day and once daily frequency. It could be transiently associated with tooth eruption, and also due to a possibility that some of the school children did not brush as they claimed, and among adults, it could be due to short brushing time, or the use of an ineffective brushing technique.

The level of awareness of the caretakers (who spent most of the time of the day with them) toward oral health was not assessed. This could be a limitation as they can guide this special group well toward the maintenance of good oral hygiene.

\section{Conclusion}

Good oral hygiene index scores were found to be more among the 13-year age-group and poor was reported to be more among the 12-and 15-year age-group. Though, there was not much difference in the oral hygiene status across the age-groups. Females had better oral hygiene status and gingival status than males.

It is well known that there are threats to oral health across the lifespan. Regular orphanage-based programs of dental health education should be implemented and reinforced in this group along with their caretakers. The instructions to clean their teeth two times a day and oral hygiene should be practiced under the supervision of the caretaker.

\section{Acknowledgments}

The authors wholeheartedly thank the concerned authorities and the participants who participated in this study.

\section{References}

1. Khare V, Kosly A, Rani PJ, et al. Prevalence of dental caries and treatment needs among the orphans children and adolescents of Udaipur District Rajasthan, India. J Contemp Dent Pract 2012;13(2):182-187. DOI: 10.5005/jp-journals-10024-1118.

2. Kumar DA, Varghese RK, Chaturvedi SS, et al. Prevalence of malocclusion among children and adolescents residing in orphanages of Bilaspur, Chattishgarh, India. J Adv Oral Res 2012;3(3):21-28. DOI: 10.1177/2229411220120304.

3. Al-Jobair AM, Al-Sadhan SA, Al-Faifi AA, et al. Medical and dental health status of orphan children in central Saudi Arabia. Saudi Med J 2013;34(5):531-536.

4. Shanbhog R, Godhi BS, Nandlal B, et al. Clinical consequences of untreated dental caries evaluated using PUFA index in orphanage children from India. J Int Oral Health 2013;5(5):1-9.

5. Srinivas R, Srinivas $P$, Viswanath $V$, et al. Oral health status of institutionalized street children aged 5-15 years in Guntur City, Andhra Pradesh, India. Int J Scient Technol Res 2012;1(1):19-23. 
6. Ojahanon $\mathrm{PI}, \mathrm{Akionbare} \mathrm{O}, \mathrm{Umoh} \mathrm{AO}$. The oral hygiene status of institution dwelling orphans in Benin City, Nigeria. Niger J ClinPract 2013;16(1):41-44. DOI: 10.4103/1119-3077.106732.

7. Gupta RK, Kharasan V, Kansal S, et al. Prevalence of dental caries, treatment need and oral hygiene practices among orphanage children. J Dent Peers 2013;1(1):1-9.

8. Pentapati KC, Acharya S, Yeturi SK. Unmet restorative treatment needs among orphanage children of Uttara Kannada District. J Educ Ethics Dent 2014;4(2):65-68. DOI: 10.4103/0974-7761.148989.

9. Toutem S, Singh V, Ganguly E. Morbidity profile of orphan children in Southern India. Int J Contemp Pediatrics 2018;5(5):1947-1951. DOI: 10.18203/2349-3291.ijcp20183537.

10. Hans R, Thomas S, Dagli RA, et al. Oral health knowledge, attitude and practices of children and adolescents of orphanages in Jodhpur City Rajasthan, India. J Clin Diagn Res 2014;8(10):22-25.

11. Muralidharan D, Fareed N, Shanthi M. Comprehensive dental health care program at an orphanage in Nellore district of Andhra Pradesh. Indian J Dent Res 2012;23(2):171-175. DOI: 10.4103/0970-9290.100421.

12. Singh A, Sequiera P, Acharya S, et al. Oral health status of two 12-yearold socially disadvantaged groups in South India: a comparative study. Oral Health Prev Dent 2011;9(1):3-7.

13. Greene JC, Vermillion JR. The simplified oral hygiene index. J Am Dent Assoc 1964;68(1):7-13. DOI: 10.14219/jada.archive.1964.0034.

14. Silness J, Loe H. Periodontal disease in pregnancy. II. Correlation between oral hygiene and periodontal condition. Acta Odont Scand 1964;22(1):121-135. DOI: 10.3109/00016356408993968.

15. Loe H, Silness J. Periodontal disease in pregnancy. I. Prevalence and severity. Acta Odont Scand 1963;21(6):533-551. DOI: 10.3109/00016356309011240.

16. Mohan A, Misra N, Umapathy D, et al. Oral and dental health status in orphan children of Lucknow. Ind J Comm Health 2014;26(2):170-173.

17. Gaur A, Sujan SG, Katna V. The oral health status of institutionalized children that is, Juvenile home and orphanage home run by Gujarat state government, in Vadodara city with that of normal school children. J Indian Soc Pedod Prev Dent 2014;32(3):231-237. DOI: 10.4103/0970-4388.135833.

18. Sushanth VH, Krishna M, Suresh Babu AM, et al. A peer group approach model of oral health promotion among orphans at Puduchery, South India. J Int Soc Prevent Communit Dent 2011;1(2):71-75. DOI: 10.4103/2231-0762.97710.

19. Camacho GA, Camacho E, Rodriguez RA, et al. Predisposing factors for dental caries in girls at an orphanage of Mexico City. Acta Pediatr Mex 2009;30(2):71-76.

20. Al-Maweri SA, Al-Soneidar WA, Halboub ES. Oral lesions and dental status among institutionalized orphans in Yemen: a matched casecontrol study. Contemp Clin Dent 2014;5(1):81-84. DOI: 10.4103/0976237X.128673.

21. Biesbrock AR, Patricia AW, Bartizek RD. Initial impact of a national dental education program on the oral health and dental knowledge of children. J Contemp Dent Pract 2003;4(2):1-7. DOI: 10.5005/jcdp4-2-1.

22. Chapman A. An oral health education programme based on the national curriculum. Int J Paediatr Dent 2006;16(1):40-44. DOI: 10.1111/j.1365-263X.2006.00677.x.

23. Prabhu R. Effect of dental health education on dental attendance of 8-9 year old school children belonging to low socioeconomic status. Karnataka State Dent J 2006:25:10-14.

24. Mazhari F, Ajami BAM, Ojrati N. Dental treatment needs of 6-12-year old children in mashhad orphanages. J Mash Dent Sch 2008;32(1):8185.

25. Khursheed DA, Zardawi FM, Abdul SO, et al. Effects of toothbrushing maneuver on gingival health status. IOSR J Dent Med Sci 2015;14(9):9096.

26. Kuppuswamy VL, Murthy S, Sharma S, et al. Oral hygiene status, knowledge, perceptions and practices among school settings in rural South India. OHDM 2012;13(1):146-154. 